\title{
Isolated Sphenoid Sinus Mucocele Presented as Orbital Apex Syndrome
}

\author{
Maryam Naser MD* and Nafiseh Hashemi MD \\ Neuro-ophthalmology Clinic, Hashemi Eye Care, USA
}

*Corresponding author: Maryam Naser MD, Neuro-ophthalmology Clinic, Hashemi Eye

Received Date: August 14, 2019

Care, Encino, California, USA.

Published Date: August 20, 2019

\begin{abstract}
Sphenoid sinus mucocele is a rare complication of chronic sinusitis. It may cause orbital apex syndrome presenting with vision loss (cranial nerve II), diplopia (cranial nerve III, IV and VI). We are presenting a case of VI nerve palsy in a middle age man with longstanding history of chronic sinusitis.
\end{abstract}

\section{Introduction}

A 62-year-old male presented with horizontal diplopia to neuro-ophthalmology office on November 2018. He recently had a cold and was having mucus discharge on the left eye and sinus headaches. He was hospitalized and had CT scan and was told he had sinus infection. After a week he developed diplopia. On his presentation, he denied any headaches or fever. He subsequently underwent MRI which showed mucocele formation of the left lateral recess of the sphenoid sinus causing narrowing of the left orbital apex compared with the right. The patient developed optic neuropathy due to pressure effect of mucocele. In eye exam, Visual field test (Humphrey 24-2) had mild inferior arcuate defect pattern in the left eye (MD: -1.98). Visual field defect of the right eye was normal. OCT optic nerve showed mild RNFL thinning on the left eye. The patient received IV antibiotics stat and was referred to neurosurgeon. He underwent left craniotomy with posterolateral orbitotomy approach. Sphenoid sinus mucocele was encasing patient's left orbital apex causing optic neuropathy and abducens nerve palsy. His double vision from sixth nerve palsy resolved completely and immediately after surgery. Left visual field defect worsened after surgery (MD= -13.17) secondary to drilling of the bone in the medial wall of the optic canal (Figure 1,2).

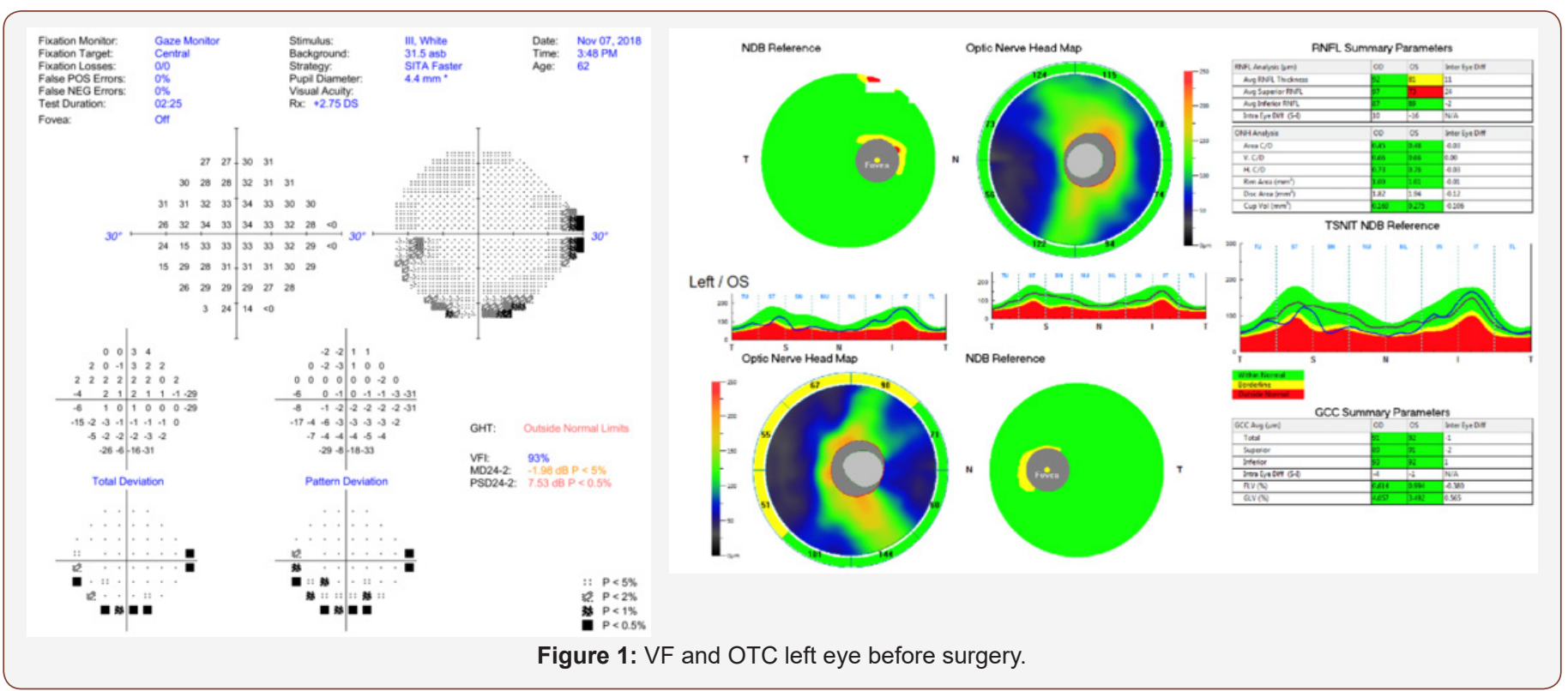




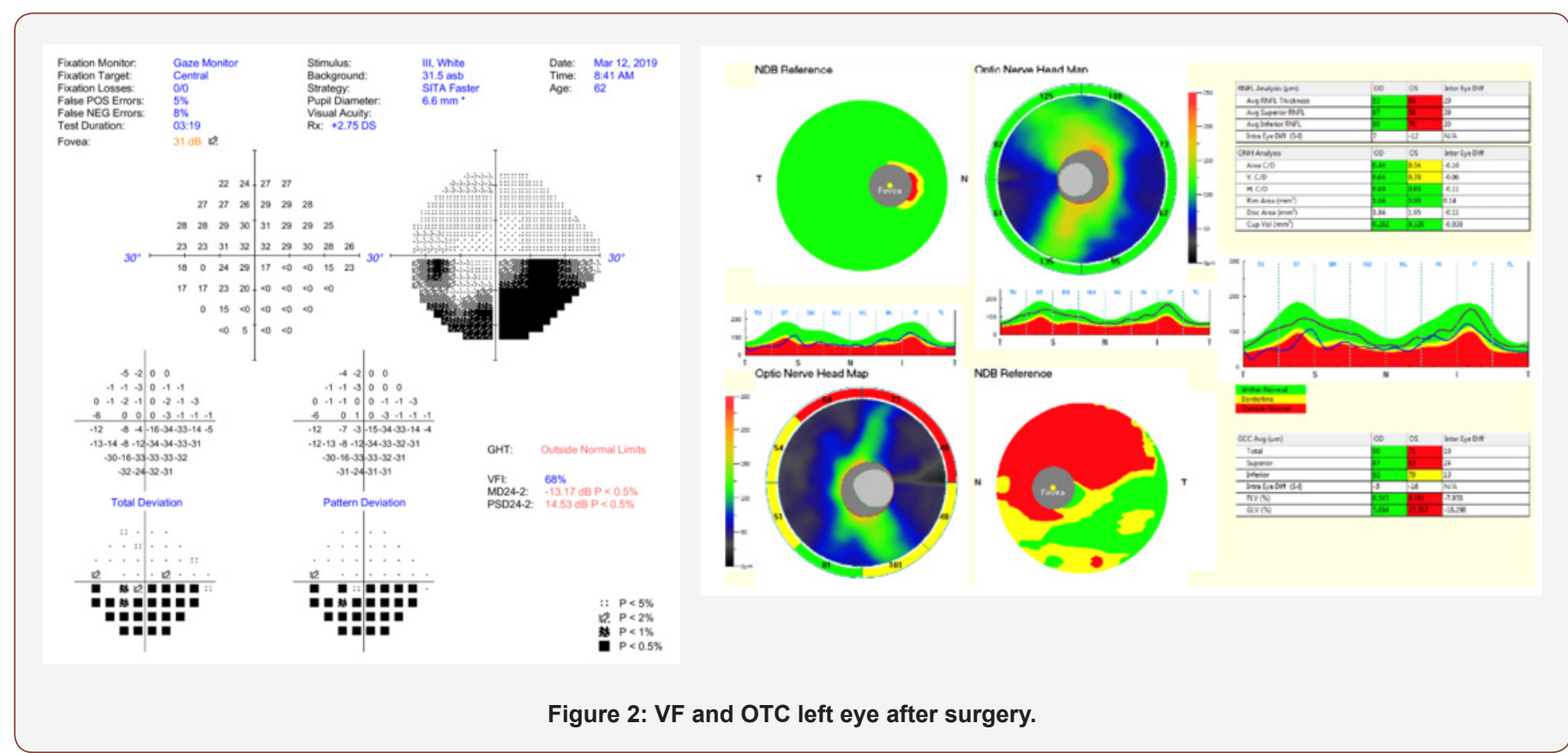

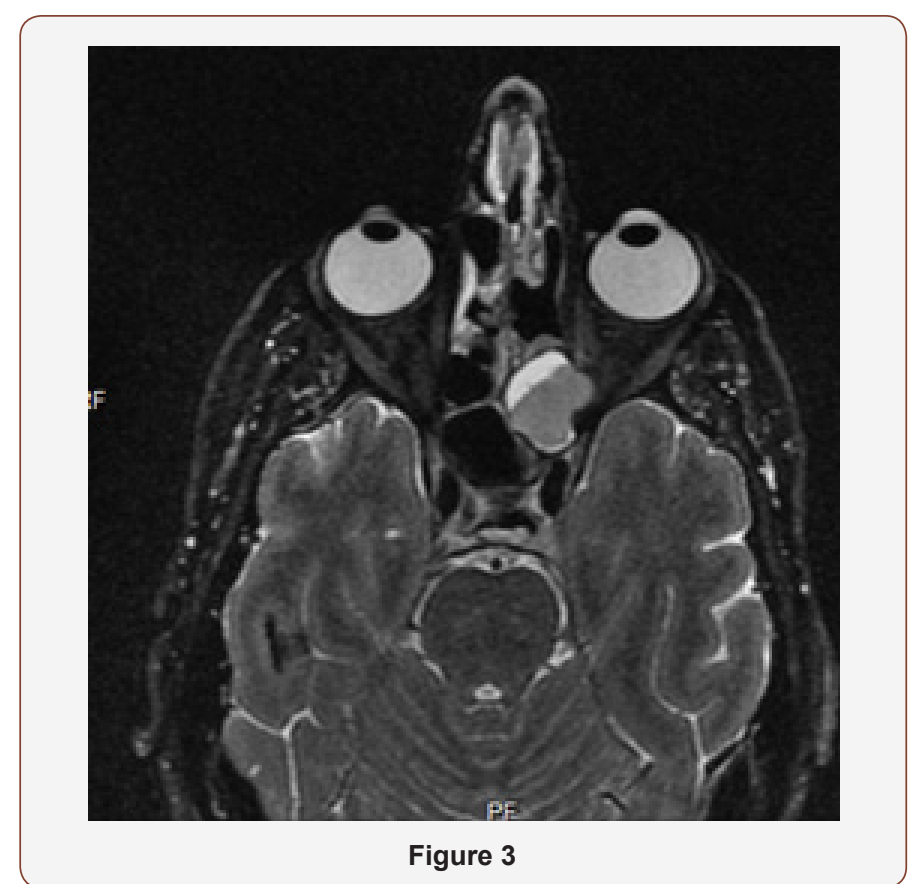

\section{Discussion}

Mucoceles are capsulated and locally invasive benign lesions expanding from paranasal sinuses, lined with respiratory epithelium. Mucoceles are commonly seen in the frontal sinuses. Sphenoid sinus mucoceles are rare [1-3]. Mucocele of the sphenoid sinus can cause bony erosion in the orbit apex, which can be seen preferably with CT scan of orbit [2]. Based on type of secretions in the mucocele it can be seen as hypo-, iso-, or hyperintense or signal void on MRI. The Mucocele usually enhances with contrast [4]. The most common presentation of sphenoid sinus mucocele is orbital apex syndrome including diplopia, cranial nerve involvement, Horner's syndrome, and proptosis [3]. Around 30-50\% of cases present with diplopia, by the oculomotor nerve being the most common involved cranial nerve [5]. The recommended surgery for sphenoid mucocele is endoscopic surgery [4]. Although, based on the location of maximum expansion of mucocele the surgical approach may be different.

Timely intervention usually results in improvement of ophthalmic manifestation, but vision may stay compromised in case of optic neuropathy [6]. Prompt surgical intervention is warranted since the visual prognosis will be guarded after 7-10 days of the onset of visual disturbance. A delay in surgery of more than seven to ten days after the onset of visual dysfunction is often associated with poor visual prognosis. Worsening vision in the treatment process is common due to vascular, inflammatory and compressive etiologies [7,8]. Our case presented with diplopia due to abducens palsy. He had blurry vision with the early signs of optic neuropathy. The prompt surgical intervention resulted in complete resolution of abducens palsy. The patient developed optic atrophy which only affected his inferior field of vision in the left eye. The progression of optic neuropathy after surgery is well known, inevitable complication of the surgery. Continued inflammation around the nerve or vascular assault during the surgery has been postulated as the reason for vision loss after surgery.

\section{Acknowledgment}

None.

\section{Conflicts of Interest}

No conflict of interest.

\section{References}

1. Friedman A, Batra PS, Fakhri S, Citardi MJ, Lanza DC (2005) Isolated sphenoid sinus disease: etiology and management. Otolaryngol Head Neck Surg 133(4) :544-550.

2. Kösling S, Hintner M, Brandt S, Schulz T, Bloching M (2004) Mucoceles of the sphenoid sinus. Eur J Radiol 51(1): 1-5.

3. Sundar U, Sharma AL, Yeolekar ME, Pahuja V (2004) Sphenoidal sinus mucocoele presenting as mono-ocular painless loss of vision. Postgrad Med J 80(939): 40. 
4. Lee JC, Park SK, Jang DK, Han YM (2010) Isolated sphenoid sinus mucocele presenting as third nerve palsy. J Korean Neurosurg Soc 48(4): 360-362.

5. Friedmann G, Harrison S (1970) Mucocoele of the sphenoidal sinus as a cause of recurrent oculomotor nerve palsy. J Neurol Neurosurg Psychiatry 33(2): 172-179.

6. Johnson LN, Hepler RS, Yee RD, Batzdorf U (1986) Sphenoid sinus mucocele (anterior clinoid variant) mimicking diabetic ophthalmoplegia and retrobulbar neuritis. Am J Ophthalmol 102(1): 111-115.
7. Lee LA, Huang CC, Lee TJ (2004) Prolonged visual disturbance secondary to isolated sphenoid sinus disease. Laryngoscope 114(6): 986-990.

8. Patt BS, Manning SC (1991) Blindness resulting from orbital complications of sinusitis. Otolaryngol Head Neck Surg 104(6): 789-795. 